\title{
Tc-99m Ser-Asp-Val-Glu-Cys-Gly: A novel Tc-99m labeled hexapeptide for molecular and non-invasive tumor imaging
}

\author{
DAE-WEUNG KIM ${ }^{1,2}$, MYOUNG HYOUN KIM ${ }^{1}$ and CHANG GUHN KIM ${ }^{1}$ \\ ${ }^{1}$ Department of Nuclear Medicine and Institute of Wonkwang Medical Science; ${ }^{2}$ Research Unit of Molecular Imaging Agent, \\ Wonkwang University School of Medicine, Iksan, Jeollabuk-do 570-711, Republic of Korea
}

Received September 22, 2015; Accepted September 26, 2016

DOI: $10.3892 / \mathrm{mmr} .2016 .5811$

\begin{abstract}
In a ProteoChip-based screening system and subsequent studies, serine-aspartic acid-valine (SDV) was demonstrated to specifically bind to integrin $\alpha v \beta 3$. An SDV-containing peptide could target the tumor vessel and it may be an effective replacement for molecular imaging of the tumor. In the present study, a hexapeptide, SDV-glutamic acid-cysteine-glycine (ECG), was developed and evaluated its diagnostic performance as a tumor imaging agent in tumor-bearing mice. The hexapeptide SDV-ECG was synthesized using Fmoc solid-phase peptide synthesis. Following radiolabeling procedures with technetium- $99 \mathrm{~m}$, the Tc-99m SDV-ECG complexes were prepared at high yields $(>97 \%)$. The uptake of Tc-99m SDV-ECG within HT-1080 tumor cells (integrin $\alpha v \beta 3$-positive) was confirmed by in vitro studies. $\gamma$-camera imaging revealed substantial uptake of Tc- $99 \mathrm{~m}$ SDV-ECG in the HT-1080 cell line tumor murine model. With the co-injection of excess SDV, tumoral uptake was blocked. Furthermore, HT-29 tumor cells (integrin $\alpha v \beta 3$-negative) and inflammatory lesions demonstrated minimal uptake of Tc-99m SDV-ECG. In the present study, Tc-99m SDV-ECG was developed as a novel Tc-99m agent for tumor imaging. The current in vitro and in vivo studies demonstrated specific functions of Tc-99m SDV-ECG in tumor imaging.
\end{abstract}

\section{Introduction}

Angiogenesis is one of the characteristics of tumor progression and it has been regarded as essential for tumor growth and metastasis (1). A number of proteins are not expressed, or are expressed at low levels, by the endothelium of normal blood vessels that are upregulated in angiogenic blood vessels of the

Correspondence to: Dr Chang Guhn Kim, Department of Nuclear Medicine and Institute of Wonkwang Medical Science, Wonkwang University School of Medicine, 344-2 Shinyong-Dong, Iksan, Jeollabuk-do 570-711, Republic of Korea

E-mail: akaxan@nate.com

Key words: serine-aspartic acid-valine, Tc-99m, tumor imaging agent, integrin $\alpha v \beta 3$ tumor, including integrin $\alpha v \beta 3$ (2), vascular endothelial growth factor receptor (3), and aminopeptidase N (4). Numerous peptides, such as arginine-glycine-aspartic acid (RGD), glutamic acid-leucine-arginine and asparagine-glycine-arginine, have been reported and evaluated $(2,5,6)$.

Lee et al (7) identified a novel peptide sequence containing serine-aspartic acid-valine (SDV) using the ProteoChip-based screening system (7). In their subsequent studies, SDV peptide was demonstrated to bind specifically to the same binding site (integrin $\alpha v \beta 3$ ) as RGD peptide, and induce upregulation of tumor protein p53 in human umbilical vein endothelial cells $(8,9)$. Despite the desirable specific binding of SDV peptide to integrin $\alpha v \beta 3$, there have been no previous efforts to develop an imaging agent for tumors using the SDV sequence. Molecular imaging targeted to angiogenesis has potential for clinical use, and as a research tool in tumor biology and in the development of therapeutic agents.

Accurate distinguishing of cancer and inflammation is important for cancer diagnosis. Due to the overlap of biochemical and imaging features, differentiation of an inflammation from malignancy using conventional computed tomography can be difficult (10). The diagnostic accuracy of F-18 fluorodeoxyglucose (FDG) positron emission tomography (PET) has been also compromized by acute inflammatory diseases, including tuberculosis, pneumonia, and sarcoidosis $(11,12)$. Novel tumor imaging agents discriminating malignancy from benign inflammation may provide improved patient management in a clinical setting.

The present study successfully developed technetium- $99 \mathrm{~m}$ SDV-glutamic acid-cysteine-glycine (ECG) to target the integrin $\alpha v \beta 3$ of tumor cells. Furthermore, the diagnostic performance of Tc-99m SDV-ECG as a tumor molecular imaging agent was evaluated in the murine model. Furthermore, the potential of Tc-99m SDV-ECG in differentiating tumors from inflammatory lesions was considered.

\section{Materials and methods}

$1 \mathrm{~N}-\mathrm{HCl}$, sodium tartrate, ethanol, $\mathrm{SnCl}_{2}$ and Freund's complete adjuvant (FCA) were purchased from Sigma-Aldrich (Merck Millipore, Darmstadt, Germany). Silica gel-coated thin-layer chromatography plates (ITLC-SG) were purchased from Gelman Sciences (Ann Arbor, MI, USA). A fresh Tc-99m pertechnetate solution was eluted from a commercial 
Mo-99/Tc-99m generator (Covidien, Ltd., Dublin, Ireland) at Wonkwang University School of Medicine (Iksan, Korea).

Chemical synthesis of peptides. Peptides were obtained from Peptron, Inc. (Daejeon, Korea) and the purity of the peptides was $>98 \%$. The peptides were synthesized using Fmoc solid-phase peptide synthesis (SPPS) with ASP48S (Peptron Inc., Daejeon, Korea). Reverse phase high-performance liquid chromatography (RP-HPLC) with a Vydac Everest column (C28, 250x22 mm, $10 \mu \mathrm{m}$; W.R. Grace \& Co., Columbia, MD, USA) was used to purify the synthesized compound. Gradients used for elution were linear from $0-75 \%$ acetonitrile in water containing $0.1 \%$ trifluoroacetic acid. LC/mass spectrometry (LC/MS) was used to confirm the purified peptide molecular weights.

Tc-99m radiolabeling study. Radiolabeling of SDV-ECG with Tc-99m was conducted using a previously described method (13). Briefly, $30 \mu 1$ of the SDV-ECG solution $(10 \mathrm{mg} / \mathrm{ml}$ in nitrogen-purged water) and $30 \mu \mathrm{l}$ of sodium tartrate $(100 \mathrm{mg} / \mathrm{ml}$ in nitrogen-purged water) were added and mixed in a microcentrifuge tube. In the tartrate solution with SDV-ECG, $100 \mu 1$ of Tc-99m pertechnetate ( $144 \mathrm{MBq})$ and $30 \mu 1 \mathrm{SnCl}_{2}(1 \mathrm{mg} / \mathrm{ml}$ in $0.01 \mathrm{M} \mathrm{HCl})$ were added. The solution was heated to $95^{\circ} \mathrm{C}$ for $30 \mathrm{~min}$ and cooled. A radio-RP-HPLC system was used to purify Tc-99m SDV-ECG. Gradients used for elution were linear from 30 to $90 \%$ acetonitrile in water containing $0.1 \%$ trifluoroacetic acid for $25 \mathrm{~min}$ at a flow rate of $2 \mathrm{ml} / \mathrm{min}$. A UV detector $(220 \mathrm{~nm})$ and a $\gamma$-radiodetector was used for monitoring.

The stability of the radiolabeling was evaluated by incubating the Tc-99m SDV-ECG in saline at room temperature. Following incubation, ITLC-SG with saline and acetone as the mobile phase was used to measure the radiolabeling efficiency at $15 \mathrm{~min}, 1,4$ and $8 \mathrm{~h}$ after radiolabeling (3 samples).

Measurement of tumor cell binding affinity. The binding affinity of Tc-99m ECG (control for non-specific uptake) and Tc-99m SDV-ECG in tumor cells was measured by saturation binding studies as previously described (14). The integrin $\alpha v \beta 3$-positive HT-1080 human fibrosarcoma cells and the integrin $\alpha v \beta 3$-negative HT-29 human colorectal carcinoma cells were obtained from the Korean Cell Line Bank (Seoul, Korea). The required cell densities of HT-1080 and HT-29 cells $\left(1 \times 10^{5}\right.$ cells/plate) were obtained by plating cells uniformly and incubating for $24 \mathrm{~h}$. The cells were washed twice using ice-cold binding buffer [ $25 \mathrm{mM}$ HEPES and $1 \%$ bovine serum albumin (Amresco, LLC, Solon, OH, USA)] and incubated for $1 \mathrm{~h}$ at $37^{\circ} \mathrm{C}$ with different concentrations $(0-800 \mathrm{nM})$ of Tc-99m ECG and Tc-99m SDV-ECG. Subsequently, the cells were washed with ice-cold binding buffer three times, and lysed using lysis buffer. Using a $\gamma$-counter (1480 Wizard 3; PerkinElmer, Inc., Waltham, MA, USA), the radioactivity was measured. The maximum number of binding sites $\left(\mathrm{B}_{\max }\right)$ and apparent dissociation constant $\left(\mathrm{K}_{\mathrm{d}}\right)$ was determined using non-linear regression models in GraphPad Prism software (version 5.03; GraphPad Software, Inc., La Jolla, CA, USA).

Murine models with tumor and inflammation. Female athymic nude mice (BALB/c nu/nu; age, 6 weeks; weight,<smiles>CC(C)C(NC(=O)C(CC(=O)O)NC(=O)C(N)CO)C(=O)NC(CCC(=O)O)C(=O)NC(CS)C(=O)NCC(=O)O</smiles>

Figure 1. Chemical structures of SDV-ECG hexapeptide. SDV-ECG, serine-aspartic acid-valine-glutamic acid-cysteine-glycine.
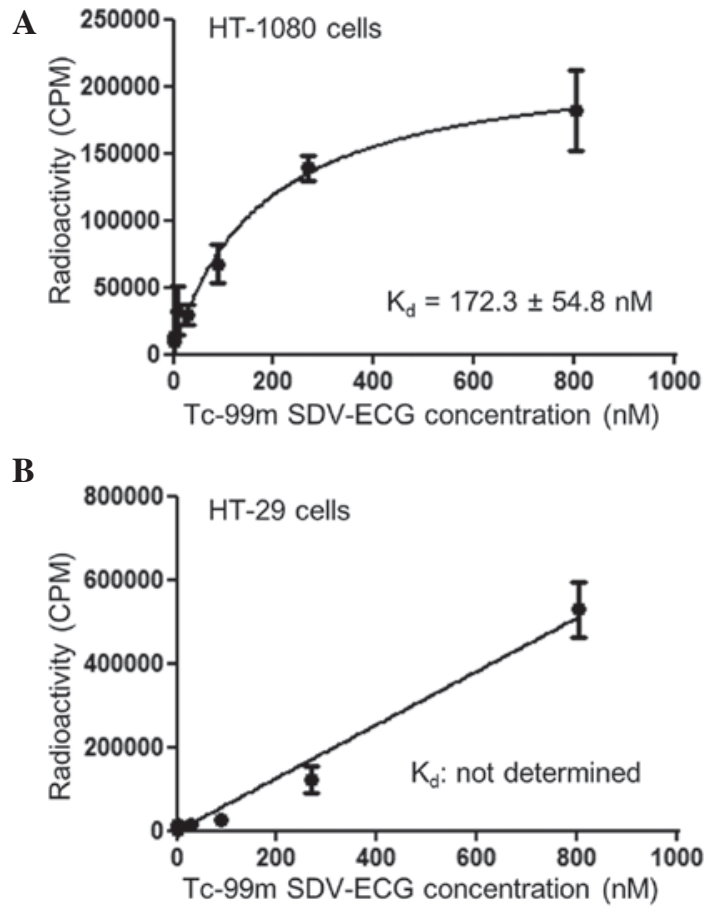

Figure 2. Cell binding affinity curves of Tc-99m SDV-ECG in (A) HT-1080 (integrin $\alpha v \beta 3$-positive) and (B) HT-29 (integrin $\alpha v \beta 3$-negative) cells. SDV-ECG, serine-aspartic acid-valine-glutamic acid-cysteine-glycine; $\mathrm{K}_{\mathrm{d}}$, equilibrium dissociation constant.

16-18 g) were purchased from Damul Science (Daejeon, Korea). Mice were housed at a density of 5 mice per cage and maintained in a specific pathogen-free unit with room temperature and humidity regulated $\left(21 \pm 2^{\circ} \mathrm{C} ; 55 \pm 10 \%\right)$ and a 12/12 h light/dark cycle. Mice were given water and alfalfa-free breeding diet). Suspended HT-1080 (1x10 $/ 0.1 \mathrm{ml})$ and HT-29 (1x10 $/ 0.1 \mathrm{ml})$ cells were subcutaneously inoculated on each side of the anterior chest region to produce an orthotopic cancer model in nude mice $(n=10)$. The $\gamma$-camera imaging and biodistribution studies were performed when the tumor diameter reached $10 \mathrm{~mm}$ ( $\sim 10$ days after inoculation). Intramuscular injection of FCA $(25 \mu \mathrm{l})$ into the right thigh region was used to induce inflammation in mice $(n=5)$. Saline (25 $\mu \mathrm{l})$ was injected into the left thigh region as a control. The $\gamma$-camera imaging was performed at 12 days after FCA injection.

Imaging with $\gamma$-camera. The in vivo imaging of the murine models was performed using a $\gamma$-camera (Vertex; ADAC Laboratories, Inc., Milpitas, CA, USA) following intravenous 


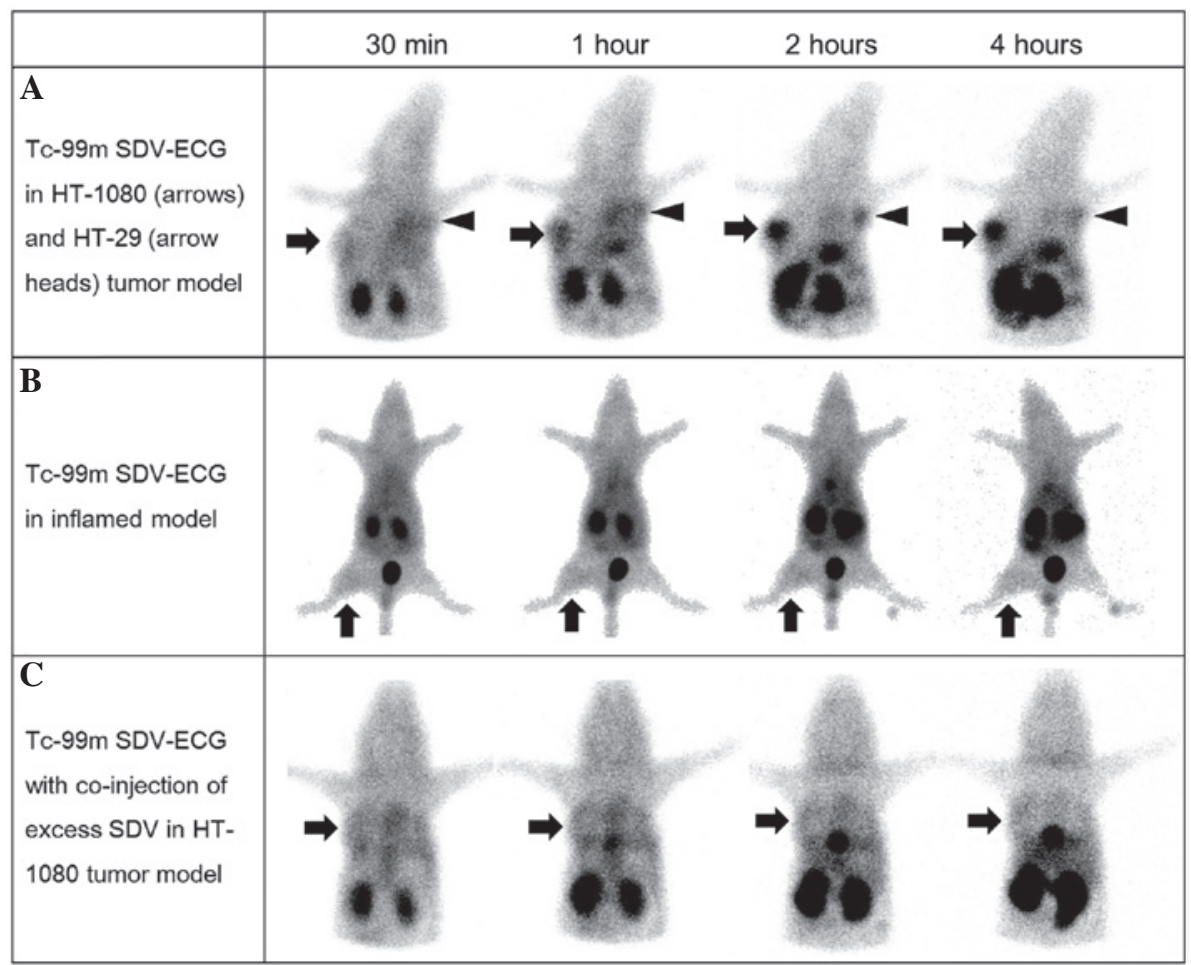

Figure 3. (A) Serial gamma camera images of HT-1080 and HT-29 tumor-bearing mice demonstrated marked uptake of Tc-99m SDV-ECG in HT-1080 tumor (integrin $\alpha v \beta 3$-positive, indicated by the arrows) and low uptake in HT-29 tumor (integrin $\alpha v \beta 3$-negative, indicated by the arrowheads. (B) In the mice model with inflammation, the inflamed lesions of the right thigh muscle demonstrated faint uptake of Tc-99m SDV-ECG. (C) Co-injection of excess concentration SDV $(10 \mathrm{mM})$ reduced the HT-1080 tumor uptake of Tc-99m SDV-ECG. SDV-ECG, serine-aspartic acid-valine-glutamic acid-cysteine-glycine.

injection of $18.5 \mathrm{MBq}$ Tc-99m SDV-ECG in tumor-bearing mice and inflammatory model mice. The in vivo $\gamma$-camera images were captured at $30 \mathrm{~min}, 1,2$ and $4 \mathrm{~h}$ after injection $(n=5)$, with acquisition times of $120 \mathrm{sec}$. The images were stored at 512x512 matrix size. In the tumor mice models, regions of interest (ROIs; $15 \times 15$ pixel sized) were drawn at the sites of the tumors on the chest walls $(n=5)$. Additional ROIs were drawn at the left arm muscle for normal muscle uptake measurement $(\mathrm{n}=5)$. In the mouse model with FCA-induced inflammation, ROIs were drawn at the right thigh (inflamed, $n=5$ ), and at the left thigh (normal muscle, $n=5$ ). The mean counts per pixel within the ROIs were measured and target-to-non-target ratios were calculated.

In vivo competition (inhibition) study with free SDV peptide. An in vivo competition study was performed to evaluate whether Tc-99m SDV-ECG specifically binds to the tumor and compete with free SDV. Excess SDV (10 mM) and Tc-99m SDV-ECG $(0.1 \mathrm{mM})$ was administered intravenously via the tail vein to mice that previously been subcutaneously inoculated with HT-1080 cells as described $(n=5)$. Serial imaging was conducted using the same manner as described above at $30 \mathrm{~min}, 1,2$, and $4 \mathrm{~h}$ after injection.

Biodistribution studies. For the biodistribution study, animals were sacrificed by cervical dislocation and each organ was dissected at 1 and $4 \mathrm{~h}$ after injection ( $\mathrm{n}=5$, per organ). Animals were dissected and selected organs and tissues were collected into pre-weighed $\gamma$-counter tubes. The radioactivity of weighed tissues was determined in a $\gamma$-counter. The counts per minute were decay-corrected, and results were expressed as a percentage injected dose per gram of wet tissue (\%ID/g). The total activities injected per animal were calculated by analyzing the difference between the initial syringe counts and the remained syringe counts following administration.

Statistical analysis. Quantitative variables were expressed as mean \pm standard deviation. One-way analysis of variance and appropriate post hoc tests were applied to compare the target-to-non-target ratios obtained from the in vivo imaging and competition studies. The data were analyzed by SPSS 18.0 (SPSS, Inc., Chicago, IL, USA). P $<0.05$ was considered to indicate a statistically significant difference.

Ethical considerations. All animal experiments were performed in accordance with guidelines of the Wonkwang University School of Medicine Committee in order to reduce the pain and sacrifice of the animals.

\section{Results}

Chemical synthesis of peptides and Tc-99m radiolabeling study. Using Fmoc SPSS, a hexapeptide, SDV-ECG $\left(\mathrm{C}_{22} \mathrm{H}_{36} \mathrm{~N}_{6} \mathrm{O}_{12} \mathrm{~S}_{1}\right.$; molecular weight, $\left.608.21 \mathrm{Da}\right)$ was synthesized (Fig. 1). A single radio-peptide species was obtained by radio- $\mathrm{RP}-\mathrm{HPLC}$ (retention time $=10.8 \mathrm{~min}$ ) following Tc-99m radiolabeling. The Tc-99m SDV-ECG complex was prepared at a high yield $(>97 \%)$ and it demonstrated high stability at room temperatures. The intact percentages of Tc-99m SDV-ECG measured by ITLC-SG were 97.6 \pm 0.2 , $97.4 \pm 0.3,96.1 \pm 0.2$ and $93.7 \pm 3.9$ at $15 \mathrm{~min}, 1,4$, and $8 \mathrm{~h}$, respectively. 


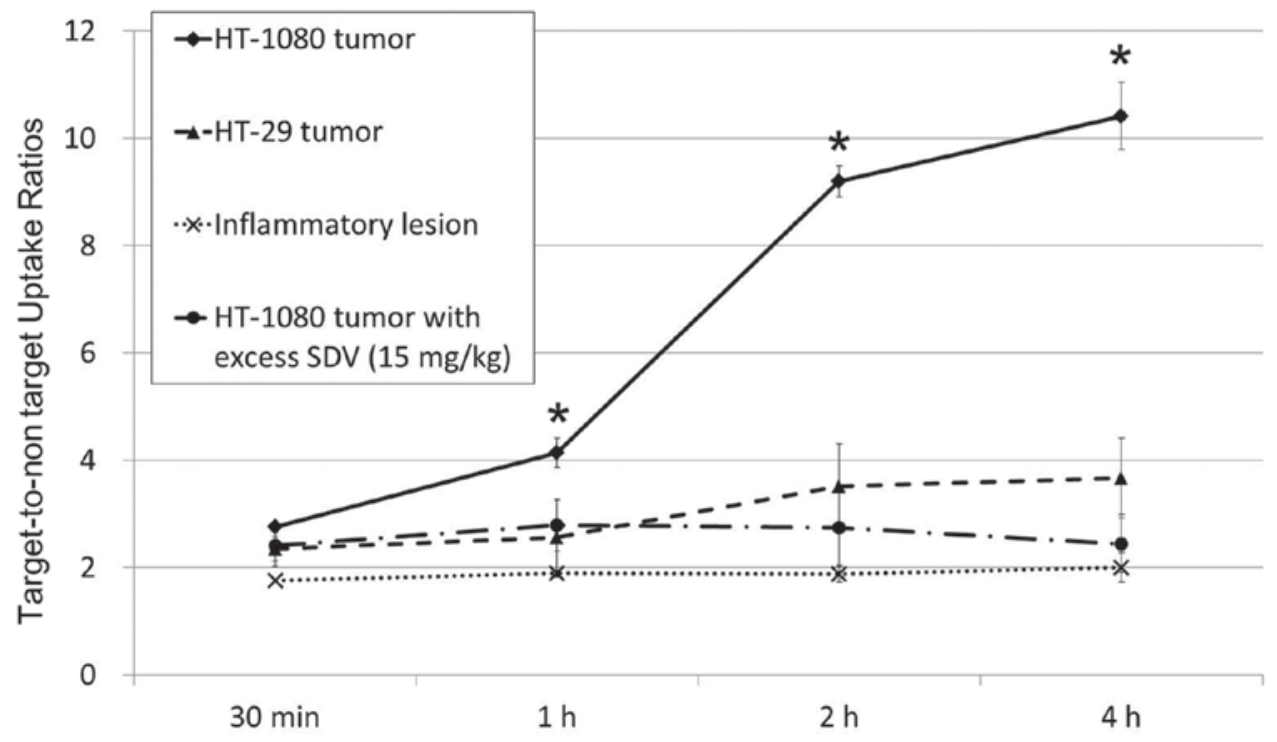

Figure 4. Target-to-non-target uptake ratio curves of Tc-99m SDV-ECG in tumor-bearing (HT-1080 and HT-29) mice and Freund's complete adjuvant-induced inflammatory mice model. At 1, 2 and $4 \mathrm{~h}$ after injection, the HT-1080 tumor-to-muscle uptake ratio of Tc-99m SDV-ECG was significantly higher than HT-29 tumor-to-muscle ("P<0.05 vs. HT-29) and inflamed-to-normal muscle uptake ratio ("P<0.05 vs. inflammatory lesion). Tumor-to-muscle uptake ratio of Tc-99m SDV-ECG was reduced by the co-injection of excess SDV (10 mM) in murine model with HT-1080 tumor ("P<0.05 vs. HT-1080 with excess SDV). SDV-ECG, serine-aspartic acid-valine-glutamic acid-cysteine-glycine.

Measurement of tumor cell binding affinity. The cell binding affinity study demonstrated that Tc-99m SDV-ECG was saturated within the integrin $\alpha v \beta 3$-positive HT-1080 tumor cells. The $\mathrm{K}_{\mathrm{d}}$ of Tc-99m SDV-ECG within the HT-1080 tumor cells determined by saturation binding was $172.3 \pm 54.8 \mathrm{nM}$ (Fig. 2A). By contrast, Tc-99m SDV-ECG was not saturated within the integrin $\alpha v \beta 3$-negative HT-29 tumor cells, and the $\mathrm{K}_{\mathrm{d}}$ value could not be determined by saturation binding (Fig. 2B).

$\gamma$-camera imaging. In the in vivo $\gamma$-camera imaging, intense activity was observed in the urinary bladder, gall bladder and bowel, suggesting Tc-99m SDV-ECG was excreted via the genitourinary and hepatobiliary systems. In the in vivo imaging of the mouse tumor model (Fig. 3), Tc-99m SDV-ECG was notably accumulated in the HT-1080 tumors, however, not in the HT-29 tumors (Fig. 3A). The HT-1080 tumor-to-normal muscle uptake ratio of Tc-99m SDV-ECG reached $10.4 \pm 0.6$ at $4 \mathrm{~h}(2.8 \pm 0.1,4.1 \pm 0.3,9.2 \pm 0.3$ and $10.4 \pm 0.6$ at $30 \mathrm{~min}, 1,2$ and $4 \mathrm{~h}$, respectively). The HT-29 tumor-to-normal muscle uptake ratios of Tc-99m SDV-ECG $(2.4 \pm 0.2,2.6 \pm 0.7,3.5 \pm 0.8$ and $3.7 \pm 0.7$ at $30 \mathrm{~min}, 1,2$ and $4 \mathrm{~h}$, respectively) were significantly lower than those of HT-1080 tumor. Furthermore, the inflamed lesions demonstrated low uptake of Tc-99m SDV-ECG. The inflammatory muscle-to-normal muscle ratios were $1.8 \pm 0.1$, $1.9 \pm 0.1,1.9 \pm 0.2$, and $2.0 \pm 0.3$ at $30 \mathrm{~min}, 1,2$, and $4 \mathrm{~h}$, respectively (Fig. 3B). The target-to-non-target ratio of the HT-1080 tumors was markedly higher than those of the HT-29 tumors and inflamed lesions at 1,2 and $4 \mathrm{~h}$ after injection, respectively ( $\mathrm{P}<0.05$; Fig. 4).

In vivo competition (inhibition) study with free SDV peptide. Co-injection of excess SDV and Tc-99m SDV-ECG was used for the competition study, it was demonstrated that the tumor-to-normal muscle uptake ratios of Tc-99m SDV-ECG was decreased $(2.4 \pm 0.4,2.8 \pm 0.5,2.8 \pm 0.7$ and $2.4 \pm 0.5$ at
30 min, 1, 2 and 4 h, respectively; Fig. 3C). It was suggested that the co-injection of excess concentration SDV blocked the uptake of Tc-99m SDV-ECG into the HT-1080 tumors $(\mathrm{P}<0.05$; Fig. 4).

Biodistribution studies. The \%ID/g values of the biodistribution of Tc-99m SDV-ECG were summarized in Table I. At 1 and $4 \mathrm{~h}$ after injection, the kidney demonstrated the highest activity $(9.81 \pm 7.58$ and $6.60 \pm 2.89$ at 1 and $4 \mathrm{~h}$, respectively). At $1 \mathrm{~h}$, the blood and the lung indicated relatively high activity (3.86 \pm 0.98 and $1.85 \pm 0.57$, respectively). At $4 \mathrm{~h}$ after injection, the majority of the organs, excluding the kidneys, indicated low activities. The \% ID/g of the HT-1080 tumor was $0.76 \pm 0.24$ and $0.39 \pm 0.06$ at 1 and $4 \mathrm{~h}$, respectively. The $\%$ ID/g of HT-29 tumor was lower than that of HT-1080 tumor $(0.65 \pm 0.25$ and $0.19 \pm 0.06$ at 1 and $4 \mathrm{~h}$, respectively). HT-1080 tumor-to-normal muscle ratios of \%ID/g were 1.5 and 4.6 at 1 and $4 \mathrm{~h}$, respectively.

\section{Discussion}

The present study produced an SDV-containing hexapeptide, SDV-ECG, for use as a tumor imaging agent. A substantial uptake of Tc-99m SDV-ECG into orthotopic HT-1080 tumor (integrin $\alpha v \beta 3$-positive) and low uptake of Tc-99m SDV-ECG in HT-29 tumor (integrin $\alpha v \beta 3$-negative) was demonstrated. A competition study demonstrated that HT-1080 tumor uptake was effectively blocked by the co-injection of excess concentration of SDV. These results support that Tc-99m SDV-ECG is a good surrogate for tumor imaging and Tc-99m SDV-ECG and free SDV may be internalized into tumors via the same pathways and mechanisms. Furthermore, Tc-99m SDV-ECG barely accumulated in the FCA-induced inflamed lesions. These results suggest Tc-99m SDV-ECG may be a novel molecular imaging agent to differentiate cancer from inflamed disease. 
Table I. Biodistribution data of Tc-99m serine-aspartic acid-valine-glutamic acid-cysteine-glycine in HT-1080 and HT-29 tumor-bearing mice.

\begin{tabular}{lcc}
\hline & \multicolumn{2}{c}{ Mean \% ID/g (SD) } \\
\cline { 2 - 3 } Tissue & $1 \mathrm{~h}$ & $4 \mathrm{~h}$ \\
\hline Lung & $1.85(0.57)$ & $0.32(0.16)$ \\
Heart & $0.76(0.27)$ & $0.13(0.03)$ \\
Blood & $3.86(0.98)$ & $0.59(0.12)$ \\
Liver & $1.14(0.22)$ & $0.46(0.25)$ \\
Stomach & $1.07(0.42)$ & $0.26(0.09)$ \\
Intestine & $0.72(0.32)$ & $0.22(0.11)$ \\
Kidney & $9.81(7.58)$ & $6.60(2.89)$ \\
Muscle & $0.50(0.18)$ & $0.09(0.03)$ \\
HT-1080 tumor & & \\
(integrin $\alpha v \beta 3$-positive) & $0.76(0.24)$ & $0.39(0.06)$ \\
HT-29 tumor & & \\
(integrin $\alpha v \beta 3$-negative) & $0.65(0.25)$ & $0.19(0.06)$ \\
\hline
\end{tabular}

$\mathrm{SD}$, standard deviation.

Integrins are heterodimeric glycoproteins that mediate transmembrane signals between extracellular signal molecules and an intracellular cytoskeleton $(15,16)$. They are understood to be crucial targets for therapeutic agents due to their associations with different conditions and diseases, including inflammation, osteoporosis, angiogenesis, and tumor metastasis $(17,18)$. Thus, the molecular imaging agents for an integrin receptor have been thoroughly developed (19). Short linear peptide sequences, such as RGD and leucine-aspartic acid-valine (LDV), served as a targeting motif for tumors $(20,21)$. Thus, the SDV sequence identified and evaluated by Lee et al (7-9), may be an additional and effective targeting motif for tumor imaging agents. Despite this SDV peptide binding specifically to integrin $\alpha v \beta 3$, there was no previous effort to develop a molecular imaging agent for tumors using SDV sequence. Thus, this is the first study, to the best of our knowledge, to develop an SDV-containing molecular imaging agent for tumor.

The Tc-99m labeled imaging agent includes two essential parts. One is the targeting section enabling the specific function of the agent, and the other is the chelating section binding with Tc-99m. In our previous study, the ECG tripeptide, including multiple nitrogen and one sulfur atoms demonstrated strong and stable chelation with Tc-99m, and is considered a good candidate for the Tc-99m chelating section of the imaging agent (6). Using a small peptide, such as SDV-ECG, as a Tc-99m-based molecular imaging agent has a number of advantages. Firstly, small peptides can be easily synthesized using Fmoc SPSS. Secondly, numerous small peptides may provide stable and strong chelating sequences for complexing with Tc-99m (22).

Several efforts have been reported to develop novel tumor imaging agents, indicating low accumulation in inflamed tissues. For example, van Waarde et al (23) and Sugae et al (24) have developed a positron emitter based imaging agent for the selective detection of tumors over inflammatory lesion. F-18
FDG has been demonstrated to have a marked impact on cancer patient management, thus, research efforts have been focused on the development of molecular imaging agents based on the positron emitters $(25,26)$. However, positron emitters are rarely available in institutions without a cyclotron and an expensive PET imaging system is essential (27). By contrast, Tc-99m is the most widely used radioisotopes in nuclear medicine and has excellent physical characteristics $(140.5 \mathrm{keV}$ emission of $89 \%$ abundance, decay by isomeric transition) for in vivo imaging. While the research developing positron emitter based imaging agent is developing, the development of Tc-99m based tumor imaging agent remains important when increasing global demand of Tc-99m is considered (28).

In conclusion, Tc-99m SDV-ECG was developed as a novel Tc-99m agent for tumor imaging. Tc-99m SDV-ECG demonstrated a substantial uptake in HT-1080 tumors, and it is a good candidate for integrin $\alpha v \beta 3$-positive tumor imaging. Furthermore, Tc-99m SDV-ECG effectively distinguished between malignant and inflamed lesions in mice.

\section{Acknowledgements}

The present study was supported by the Basic Science Research Program through the National Research Foundation of Korea (NRF) funded by the Ministry of Education (2013R1A1A2059262) and a NRF grant funded by the Korean government (MSIP: Ministry of Science, ICT and Future Planning) (2014M2B2A9030059).

\section{References}

1. Hanahan D and Weinberg RA: Hallmarks of cancer: The next generation. Cell 144: 646-674, 2011.

2. Gladson CL and Cheresh DA: Glioblastoma expression of vitronectin and the alpha v beta 3 integrin. Adhesion mechanism for transformed glial cells. J Clin Invest 88: 1924-1932, 1991.

3. Veikkola T, Karkkainen M, Claesson-Welsh L and Alitalo K: Regulation of angiogenesis via vascular endothelial growth factor receptors. Cancer Res 60: 203-212, 2000.

4. Bhagwat SV, Lahdenranta J, Giordano R, Arap W, Pasqualini R and Shapiro LH: CD13/APN is activated by angiogenic signals and is essential for capillary tube formation. Blood 97: 652-659, 2001.

5. Wang RE, Niu Y, Wu H, Amin MN and Cai J: Development of NGR peptide-based agents for tumor imaging. Am J Nucl Med Mol Imaging 1: 36-46, 2011.

6. Kim DW, Kim WH, Kim MH and Kim CG: Novel Tc-99m labeled ELR-containing 6-mer peptides for tumor imaging in epidermoid carcinoma xenografts model: A pilot study. Ann Nucl Med 27: 892-897, 2013

7. Lee Y, Kang DK, Chang SI, Han MH and Kang IC: High-throughput screening of novel peptide inhibitors of an integrin receptor from the hexapeptide library by using a protein microarray chip. J Biomol Screen 9: 687-694, 2004.

8. Choi Y, Kim E, Lee Y, Han MH and Kang IC: Site-specific inhibition of integrin alpha $\mathrm{v}$ beta 3 -vitronectin association by a ser-asp-val sequence through an Arg-Gly-Asp-binding site of the integrin. Proteomics 10: 72-80, 2010.

9. Bang JY, Kim EY, Kang DK, Chang SI, Han MH, Baek KH and Kang IC: Pharmacoproteomic analysis of a novel cell-permeable peptide inhibitor of tumor-induced angiogenesis. Mol Cell Proteomics 10: M110.005264, 2011.

10. Dutta AK and Chacko A: Head mass in chronic pancreatitis: Inflammatory or malignant. World J Gastrointest Endosc 7: 258-264, 2015 .

11. Takamochi K, Yoshida J, Murakami K, Niho S, Ishii G, Nishimura M, Nishiwaki Y, Suzuki K and Nagai K: Pitfalls in lymph node staging with positron emission tomography in non-small cell lung cancer patients. Lung Cancer 47: 235-242, 2005. 
12. Kubota R, Kubota K, Yamada S, Tada M, Ido T and Tamahashi N: Microautoradiographic study for the differentiation of intratumoral macrophages, granulation tissues and cancer cells by the dynamics of fluorine-18-fluorodeoxyglucose uptake. J Nucl Med 35: 104-112, 1994.

13. Kim DW, Kim WH, Kim MH and Kim CG: Synthesis and evaluation of novel Tc-99m labeled NGR-containing hexapeptides as tumor imaging agents. J Labelled Comp Radiopharm 58: 30-35, 2015.

14. Wu C, Wei J, Gao K and Wang Y: Dibenzothiazoles as novel amyloid-imaging agents. Bioorg Med Chem 15: 2789-2796, 2007.

15. Albelda SM and Buck CA: Integrins and other cell adhesion molecules. FASEB J 4: 2868-2880, 1990.

16. Humphries MJ: Integrin structure. Biochem Soc Trans 28: 311-339, 2000

17. Mousa SA: Anti-integrin as novel drug-discovery targets: Potential therapeutic and diagnostic implications. Curr Opin Chem Biol 6: 534-541, 2002.

18. Tucker GC: Inhibitors of integrins. Curr Opin Pharmacol 2 : 394-402, 2002.

19. Carman CV: Overview: Imaging in the study of integrins. Methods Mol Biol 757: 159-189, 2012.

20. Gaertner FC, Kessler H, Wester HJ, Schwaiger M and Beer AJ: Radiolabelled RGD peptides for imaging and therapy. Eur J Nucl Med Mol Imaging 39 (Suppl 1): 126-138, 2012.

21. Shi P, Chen H, Cho MR and Stroscio MA: Peptide-directed binding of quantum dots to integrins in human fibroblast. IEEE Trans Nanobioscience 5: 15-19, 2006.
22. Liu S and Edwards DS: 99mTc-Labeled small peptides as diagnostic radiopharmaceuticals. Chem Rev 99: 2235-2268, 1999.

23. van Waarde A, Jager PL, Ishiwata K, Dierckx RA and Elsinga PH: Comparison of sigma-ligands and metabolic PET tracers for differentiating tumor from inflammation. J Nucl Med 47: 150-154, 2006.

24. Sugae S, Suzuki A, Takahashi N, Minamimoto R, Cheng C, Theeraladanon C, Endo I, Togo S, Inoue T and Shimada H: Fluorine-18-labeled 5-fluorouracil is a useful radiotracer for differentiation of malignant tumors from inflammatory lesions. Ann Nucl Med 22: 65-72, 2008.

25. Fazaeli Y, Jalilian A, Amini M, Ardaneh K, Rahiminejad A, Bolourinovin F, Moradkhani S and Majdabadi A: Development of a (68)Ga-fluorinated porphyrin complex as a possible PET imaging agent. Nucl Med Mol Imaging 46: 20-26, 2012.

26. Shin KH, Park SA, Kim SY, Lee SJ, Oh SJ and Kim JS: Effect of animal condition and fluvoxamine on the result of [18F]N-3Fluoropropyl-2 $\beta$-carbomethoxy-3 $\beta$-(4-iodophenyl) Nortropane ([18F]FP-CIT) PET study in mice. Nucl Med Mol Imaging 46: 27-33, 2012.

27. Berger M, Gould MK and Barnett PG: The cost of positron emission tomography in six United States veterans affairs hospitals and two academic medical centers. AJR Am J Roentgenol 181: 359-365, 2003.

28. Matthews KM, Bowyer TW, Saey PR and Payne RF: The workshop on signatures of medical and industrial isotope production-WOSMIP; Strassoldo, Italy, 1-3 July 2009. J Environ Radioact 110: 1-6, 2012. 